\title{
Study the Effect of Doping with Chromium Chloride on Silica Aerogel Properties Prepared with Ambient Pressure
}

\author{
Israa F. Al-Sharueez ${ }^{1}$ and Wesam A A Twej ${ }^{2}$ \\ ${ }^{1}$ Al-Mustansiriyah University, College of Science, Physics Department. \\ ${ }^{2}$ University of Baghdad, College of Science, Physics Department.
}

\begin{abstract}
Hydrophobic silica aerogel have been prepared through two step acid-base catalysis recipe, via ambient pressure drying method. tetraethylorthosilicate was used as precursor, and trimethylchlorosilan as surface modifier. Three adopted molar concentrations of Chromium chloride are used; 0.019, 0.032, 0.051 [M]. In this paper, the molar ratio of chemicals; precursor, alcohol and catalyst, was kept constant at (1:8.6:0.23) respectively. The hydrophobic property was obtained by socking the final gel in trimethylchlorosilan -hexane solution at $6 \mathrm{wt}$. \% of modifiers in hexane. The physical properties of the prepared aerogel samples; optical, structural and morphological were examined through UV-VIS spectroscopy, FTIR spectra, X ray diffraction, contact angle measurement and field emission scanning electron microscopy. The results indicate that, the doping process offers an enhancement of the aerogel hydrophobic property. As well as, the doped aerogel being of lower density, relatively have smaller particle size and of more homogenous surface.
\end{abstract}

Keywords: Chromium chloride, ambient drying, contact angle, doping, oxidation.

\section{Introduction:}

Aerogel, are sol-gel material dried in a carefully controlled procedure to preclude pore collapse, leaving an unharmed solid nanostructure in a material that contains (90-99) $\%$ of air by volume [1]. Silica aerogel has mostly an open configuration with a very low density (typically $0.01 \mathrm{~g} / \mathrm{cm}^{3}$ ), high specific surface area $(650-1100) \mathrm{m}^{2} / \mathrm{g}$, exceedingly highporosity $(90-98) \%$ and low thermal conductivity $(0.01 \mathrm{~W} / \mathrm{mK})$ [2-4]. It is common practice to prefix the word gel with whatever makes up the fluid component. Hence, alcogel is filled with alcohol, hydrogel is filled with water, wet gel is filled with a general liquid or mixture of liquids and..., aerogel is filled with air [5].

The unique combination of structural and thermal properties makes it an attractive material for a multiplicity of applications ranging from platforms for thermal insulation to chemical sensors [6-8]. Energy storage and heat, catalyst supports, battery electrodes, humidity sensors and gas, adsorbents, and drug delivery systems, etc. [5, 9-12]. The first report of aerogel by Kistler, published in Nature (1931), was enabled by the invention of supercritical drying (SCD) and appeared in a letter. SCD is a technique of converting liquid to gas without the two phases being present at the same time, consequently allowing the structure of the gel to be conserved but the pores to be filled with gas [13]. The continuous nature of wet-gels was well concept at this time, but substituting the liquid phase with gas was until now impossible because capillary forces during evaporation collapse the fragile structures [14]. An aerogel is made "by ( $\mathrm{SiO} 2)$ during this process, organic compounds containing silica undergo a chemical reaction making silicon oxide [15]. Metal doped silica composite aerogel has been applied successfully in many reactions of catalytic oxidation, hydrogenation and dehydrogenation as high efficiency catalysts [16]. Strong influence on the physical properties such as apparent density, volume shrinkage, contact angle, thermal conductivity and optical transparency, etc. [17]. In general metal particles are found to be trapped in the host of silica matrix in very small amount without any bonding with silica network, confirmed by the AAS studies [18]. In the present paper, Chromium chloride doped hydrophobic aerogels have been prepared through two step acid base recipe and via ambient pressure drying method. The influence of doping concentration on physical and morphological properties have been investigated.

\subsection{Chemical materials}

\section{Experimental}

The chemical materials used in this work were; Tetraethylorthosilicate (TEOS) $98 \%$, Trimethylchlorosilan (TMCS) > 98.0 \%, n-Hexane > 98.0\%, all supplied from Sigma Aldrich, Chromium chloride hexahydrate $97 \%$ Fluka, , hydrochloric acid $(\mathrm{HCl})>99.0 \%$ Qualigens Fine Chemicals, Ammonia solution $\left(\mathrm{NH}_{3}\right.$, Merck, India), Ammonium Fluoride $\left(\mathrm{NH}_{4} \mathrm{~F}\right.$, LobaChemie). 
Study the Effect of Doping with Chromium Chloride on Silica Aerogel Properties Prepared W...

\subsection{Sample preparation}

Silica aerogels were prepared through a two-step acid-base catalyzed sol-gel process followed by ambient pressure drying. The sol was prepared using TEOS, ethanol and $\mathrm{HCl}(0.01 \mathrm{M})$, recipe molar ratio of TEOS, EthOH, $\mathrm{HCl}$, was (1:8.6:0.23)respectively. After $48 \mathrm{~h}$ of hydrolysis three molar concentration of $\mathrm{CrCl}_{3}$ $6 \mathrm{H}_{2} \mathrm{O}$ were add to the solution $(0.019,0.032$ and $0.051[\mathrm{M}])$. Drop by drop amount of $\left(50 \% \mathrm{NH}_{4} \mathrm{OH}, 50 \%\right.$ $\mathrm{NH}_{4} \mathrm{~F}$ ) solution were added to the recipe to adjusts the sol $\mathrm{pH}$ at 8.3. Greenalcogel was formed within few minutes. Ethanol and hexane mixing solution at mixing ratio of $75 \%-25 \%, 50 \%-50 \%, 25 \%-75 \%$ and $0 \%$ $100 \%$ were prepared and used for alcogel socking at rate of four days. The silica aerogels with hydrophobic property were obtained by socking the final gel in (TMCS-Hexane) solution at $6 \mathrm{wt}$ \% (TMCS) three times within three days, and finally, in pure hexane three times every day.

The gel is formed by the hydrolysis and polymerization of TEOS with $\mathrm{HCl}$ as a catalyst and metal ion as given below [19]:

Hydrolysis:

Condensation:

$$
\mathrm{Si}\left(\mathrm{OC}_{2} \mathrm{H}_{5}\right)_{4}+4 \mathrm{H}_{2} \mathrm{O} \underset{\mathrm{CuCl}_{2}}{\longrightarrow} \mathrm{Si}(\mathrm{OH})_{4}+4 \mathrm{C}_{2} \mathrm{H}_{5} \mathrm{OH}
$$

$$
\mathrm{Si}(\mathrm{OH})_{4}+\mathrm{Si}(\mathrm{OH})_{4} \underset{\mathrm{NH}_{4} \mathrm{~F}}{\stackrel{\mathrm{NH}_{4} \mathrm{OH}}{\longrightarrow}}(\mathrm{OH})_{3} \mathrm{Si}-\mathrm{O}-\mathrm{Si}(\mathrm{OH})_{3}+\mathrm{H}_{2} \mathrm{O}
$$

Modification reaction is given in the following equation;<smiles>C=[Si](O)O[Si](C)(O)O</smiles><smiles>C[Si](C)(C)Cl</smiles>
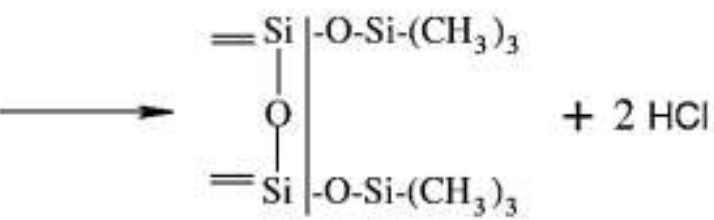

\subsection{Methods of characterization}

Since the prepared aerogel samples were of irregular shape, their densities were obtained by filling them in a cylindrical column of known volume the density was calculated from its mass to volume ratio. The surface modification was confirmed using Fourier transform infrared (FTIR) spectroscopy (Shimadzu-8400S) in the range of (400-4000) $\mathrm{cm}^{-1}$ using KBr pellets. X-ray diffractometer (XRD:Philips, model: X'Pert MPD) was used to determine the phases of doping nanosilicate. The degree of hydrophobicity was quantified by measuring the contact angle $(\theta)$ of a water droplet placed on the surface of the aerogel using a contact angle meter (RameHart instrument, USA). The microstructure of nanoporous was analyzed using Field Emission Scanning Electron Microscopy (FESEM) (Model Philips XL-30).

\subsection{Optical analysis for Chromium aeroge}

\section{Results and Discussion}

Optical characterizations were achieved through the transmittance spectra, all samples normalize with thickness. Figure (1) show the transmittance spectra of aerogel doping with Chromium chloride.



Figure (1) Transmittance spectra of aerogel doping with Chromium chloride 
As shown in figure (1), at lowest concentration $50 \%$ of incident light have been passed from sample, and at moderated concentration, $0.032[\mathrm{M}], 40 \%$ will passed. Whereas, at high doping concentration 0.052 [M] just $15 \%$ of incident light have been passed. In this work, heating is very importantto make modification, leadingheating of chromium chloride triple and subsequent cooling to a sharing in the union as illustrated in equation (3), the gradual cooling leads to its transformation into a violet color [20].

$$
\left[\mathrm{Cr}\left(\mathrm{H}_{2} \mathrm{O}\right)_{6}\right] \mathrm{Cl}_{3} \rightleftharpoons\left[\mathrm{CrCl}_{3}\left(\mathrm{H}_{2} \mathrm{O}\right)_{3}\right] 3 \mathrm{H}_{2} \mathrm{O}
$$

This is lead to get less transparency in aerogel doped with Chromium chloride.

Figure (2) present the image of Chromium chloride doped aerogels samples. It is clear that as the doping concentration increased the samples geometrical shape will deformed due to cracks caused by metal ion resulting in collapse of silica networks.
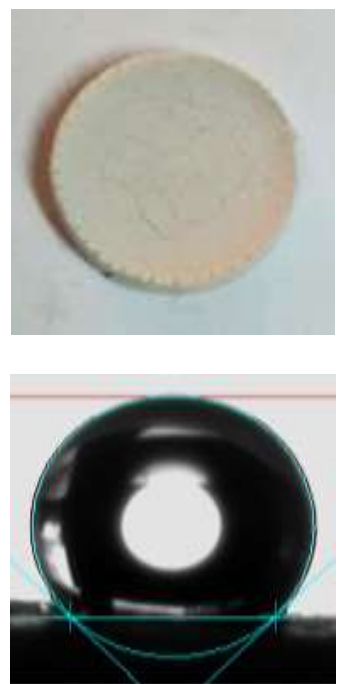

$0.019[\mathrm{M}]$
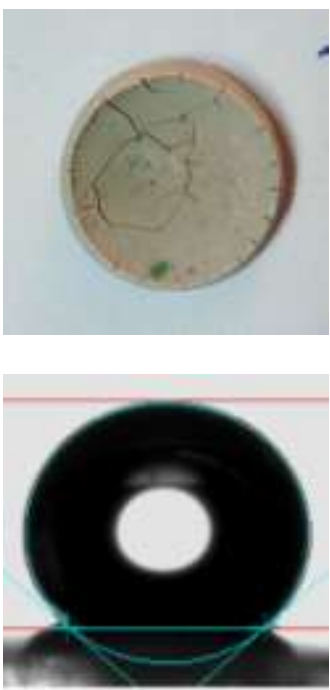

$0.032[\mathrm{M}]$
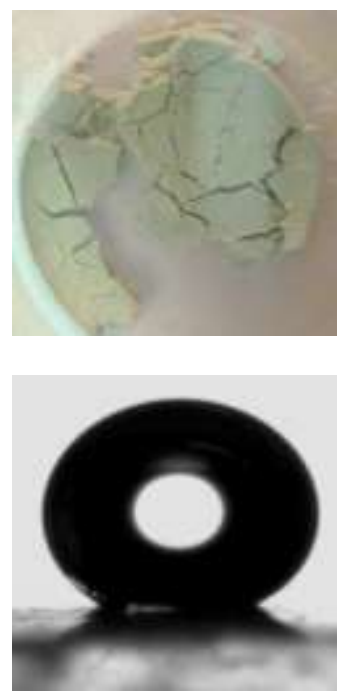

$0.052[\mathrm{M}]$

Figure (2) Photographic image of aerogel doped with Chromium chloride with different concentrations.

Table (1) displays some of properties for aerogel doped in chromium chloride. From table observed that the density increased with increasing the concentration, as well as particle size, as shown in figure (2).

Table (1) some properties of aerogel doped with Chromium chloride.

\begin{tabular}{|c|c|c|c|c|}
\hline $\begin{array}{c}\text { concentration of } \\
\mathrm{CrCl}_{3}[\mathrm{M}]\end{array}$ & $\begin{array}{c}\text { Density } \\
\mathrm{gm} / \mathrm{cm}^{3}\end{array}$ & $\begin{array}{c}\text { Contact angel } \\
\text { (degree) }\end{array}$ & $\begin{array}{c}\text { Particle size } \\
(\mathrm{nm})\end{array}$ & $\begin{array}{c}\text { Transmittance } \\
\%\end{array}$ \\
\hline 0.019 & 0.05 & 134 & 25 & 50 \\
\hline 0.032 & 0.108 & 149 & 32 & 40 \\
\hline 0.051 & 0.128 & 153.4 & 45 & 15 \\
\hline
\end{tabular}

\subsection{FTIR spectroscopy study for Chromium aerogel}

Figure (3) illustrated FTIR test for aerogel doped with Chromium chloride with different molar concentration. FTIR spectra for all concentration indicate successful surface chemical modification on aerogel doping with Chromium chloride, Furthermore, the broad bands at $\mathrm{O}-\mathrm{H}$ and at 1600 and $3400 \mathrm{~cm}^{-1}$ were being weaker, and the band of C-H at (2750) $\mathrm{cm}^{-1}$ at low concentration become stronger as concentration was increased. This may mean that the chromium ions can enhanced the replace of $-\mathrm{OH}$ groups by $\mathrm{C}-\mathrm{H}$ group. At high concentration a new peak has been appear at $679 \mathrm{~cm}^{-1}$. The initiated of this peak may be attributed to the formation of $\mathrm{Cr}-\mathrm{O}-\mathrm{Cr}$ [21]. And these bonds may help in reducing $-\mathrm{OH}$ groups.

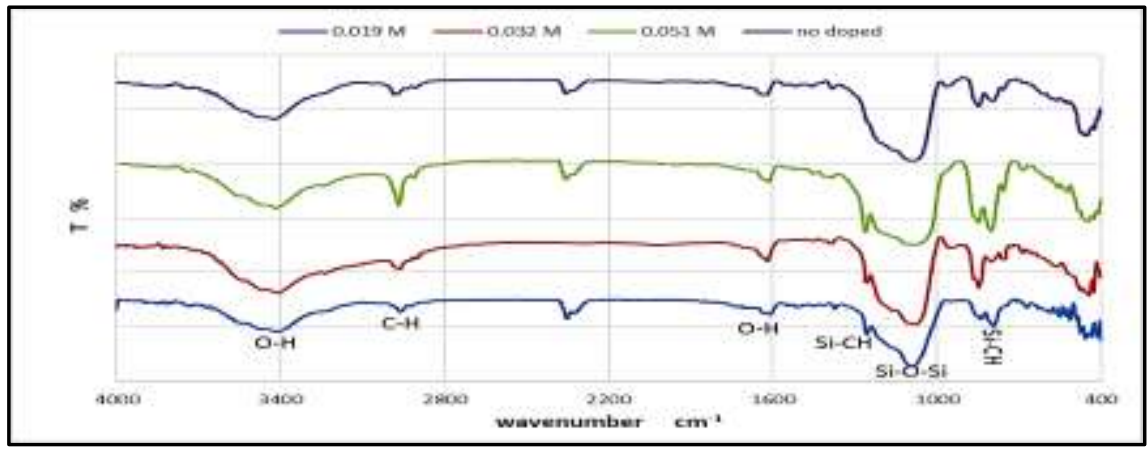

Figure (3) FTIR spectra of the aerogel doped with Chromium chloride. 
Study the Effect of Doping with Chromium Chloride on Silica Aerogel Properties Prepared W...

\subsection{X-Ray Diffraction for Chromium aerogel}

The XRD patterns for the optimized doping sample with metal ions were achieved. Figure (4) illustrated XRD for aerogel doped with Chromium chloride with highest and lowest concentration.

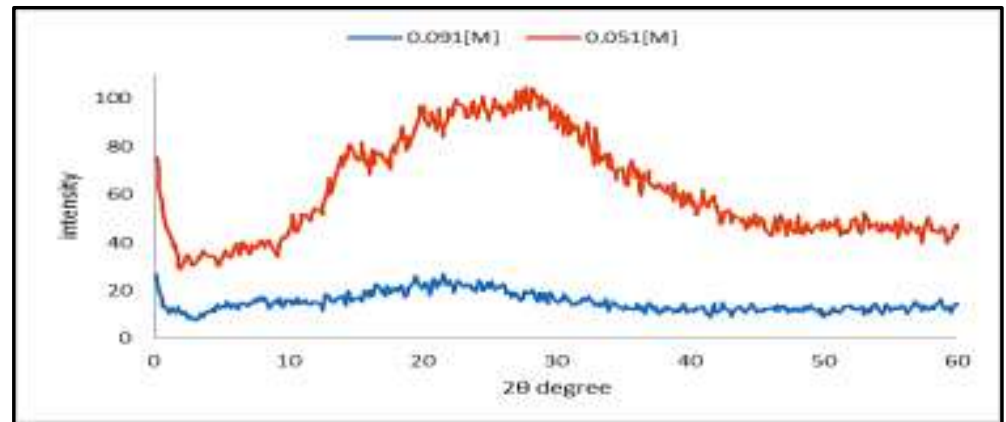

Figure (4) XRD spectra of the aerogel doped with Chromium chloride with molar concentration (0.019 and $0.051[\mathrm{M}])$.

From XRD patterns it is clear that amorphous feature was dominate for chromium doped aerogel spectra even at high doping concentration. This may be due to high temperature needed for converting chromium doped aerogel to crystalline phase. Some researchers have pointed out that the temperature of crystallization of chromium in the at least $500{ }^{\circ} \mathrm{C}[22,23]$. In the current work, the drying temperature don't rise $250^{\circ} \mathrm{C}$ in order to not lose the hydrophobic property, thus several diffraction crystalline peaks have not been seen in the XRD spectra.

\subsection{Scanning Electron Microscopy observation for Chromium aerogel}

The effect of the doping concentration on the microstructure of the silica aerogel doped with chromium chloride was observed via FESEM. Figure (5) shows the FESEM micrographs of lower and higher concentration of chromium doped silica aerogel. Particles are aggregated with original particle size is (25-45) $\mathrm{nm}$ and the shapes of particles are irregular. It can be seen that particle size slightly decreased when the doping concentration increased. At higher doping concentration, the particle size appearing of smaller size and smaller pore sizes in their structure.


$0.051[\mathrm{M}]$

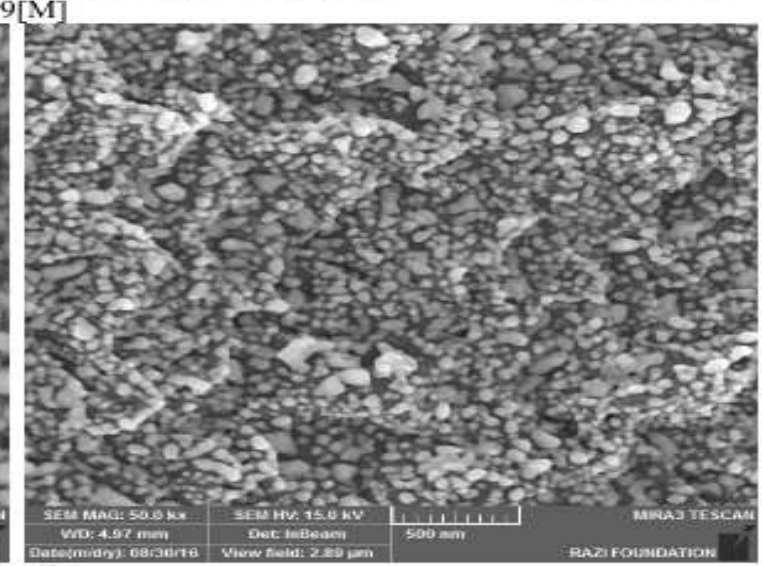

Figure (5) FESEM images, at two different magnification doping with $\mathrm{CrCl}_{3} 0.019$ [M] and 0.051 [M]. 


\section{Conclusions}

Doping silica aerogel with $\mathrm{CuCl}_{2}$ using two step acid-base catalysis via ambient pressure and can enhanced its hydrophobic property. Polycrystalline rather than amorphous feature will be initiated as the doping concentration increased resulting in large particle size, denser and more hydrophobic aerogel monolith.

\section{Acknowledgements}

The authors acknowledge Baghdad University and IbnSina Center of science for funding this research work.

\section{References}

[1]. $\quad$ M. A. Aegerter, N. Leventis, and M. Koebel, "Advances in sol-gel derived materials and technologies," ed: Springer, 2011.

[2]. D. Gu and F. Schüth, "Synthesis of non-siliceous mesoporous oxides," Chemical Society Reviews, vol. 43, pp. 313-344, 2014.

[3]. H.-x. Shi, J.-t. Cui, H.-m. Shen, and H.-k. Wu, "Preparation of silica aerogel and its adsorption performance to organic molecule," Advances in Materials Science and Engineering, vol. 2014, 2014.

[4]. A. Montes, M. Gordillo, C. Pereyra, N. de la Rosa-Fox, and E. M. de la Ossa, "Silica microparticles precipitation by two processes using supercritical fluids," The Journal of Supercritical Fluids, vol. 75, pp. 88-93, 2013.

[5]. A. C. Pierre and G. M. Pajonk, "Chemistry of aerogels and their applications," Chemical Reviews, vol. 102, pp. 4243-4266, 2002.

[6]. D. L. Plata, Y. J. Briones, R. L. Wolfe, M. K. Carroll, S. D. Bakrania, S. G. Mandel, et al., "Aerogel-platform optical sensors for oxygen gas," Journal of Non-Crystalline Solids, vol. 350, pp. 326-335, 2004.

[7]. J. E. Fesmire, "Aerogel insulation systems for space launch applications," Cryogenics, vol. 46, pp. 111-117, 2006.

[8]. G. Wei, Y. Liu, X. Zhang, F. Yu, and X. Du, "Thermal conductivities study on silica aerogel and its composite insulation materials," International Journal of Heat and Mass Transfer, vol. 54, pp. 2355-2366, 2011.

[9]. M. Antonietti, N. Fechler, and T.-P. Fellinger, "Carbon aerogels and monoliths: control of porosity and nanoarchitecture via SolGel routes," Chemistry of Materials, vol. 26, pp. 196-210, 2013.

[10]. H. Maleki, L. Durães, and A. Portugal, "An overview on silica aerogels synthesis and different mechanical reinforcing strategies," Journal of Non-Crystalline Solids, vol. 385, pp. 55-74, 2014.

[11]. R. Ciriminna, A. Fidalgo, V. Pandarus, F. Béland, L. M. Ilharco, and M. Pagliaro, "The sol-gel route to advanced silica-based materials and recent applications," Chemical reviews, vol. 113, pp. 6592-6620, 2013.

[12]. N. Leventis and H. Lu, "Aerogels Handbook, ed. MA Aegerter, N. Leventis and MM Koebel," ed: Springer, New York, 2011.

[13]. S. S. Kistler, "Coherent Expanded Aerogels and Jellies," Nature, vol. 127, p. 741, 1931.

[14]. S. Kistler, "Coherent expanded-aerogels," The Journal of Physical Chemistry, vol. 36, pp. 52-64, 1932.

[15]. C. J. Brinker and G. W. Scherer, Sol-gel science: the physics and chemistry of sol-gel processing: Academic press, 1990.

[16]. W. SHEN, C. PAN, X.-Y. YANG, and H.-L. XU, "Coupling Reaction of 1, 4-Butanediol with Maleic Anhydride over Cr-Cu/SiO 2 Catalysts," 2008

[17]. E. C. Alyea, L. J. Lakshmi, and Z. Ju, "Spectroscopic and activity studies on vanadia supported on titania and phosphorus-modified titania," Langmuir, vol. 13, pp. 5621-5626, 1997.

[18]. V. Parale, D. Mahadik, M. Kavale, A. V. Rao, R. A. Patil, Y.-R. Ma, et al., "Effect of aluminium and copper acetylacetonate on physico-chemical properties of tetraethoxysilane based silica aerogels," Journal of Porous Materials, vol. 20, pp. 563-570, 2013.

[19]. SHEN, Wei, PAN, Chao, YANG, Xin-Yan, \& XU, Hua-Long. (2008). Coupling Reaction of 1, 4-Butanediol with Maleic Anhydride over $\mathrm{Cr}-\mathrm{Cu} / \mathrm{SiO} 2$ Catalysts.

[20]. J. Wang, S. Uma, and K. Klabunde, "Visible light photocatalytic activities of transition metal oxide/silica aerogels," Microporous and mesoporous materials, vol. 75, pp. 143-147, 2004.

[21]. S. Raissi, M. Younes, and A. Ghorbel, "Synthesis and characterization of aerogel sulphated zirconia doped with chromium: nhexane isomerization," Journal of Porous Materials, vol. 17, pp. 275-281, 2010

[22]. B. Kumar, S. Kumar, and A. Ganguli, "Surface decoration through electrostatic interaction leading to enhanced reactivity: Low temperature synthesis of nanostructured chromium borides (CrB and CrB 2)," Journal of Solid State Chemistry, vol. 200, pp. 117122, 2013.

[23]. Z. Liu, Y. n. Wei, X. Meng, T. Wei, and S. Ran, "Synthesis of CrB 2 powders at $800^{\circ}$ C under ambient pressure," Ceramics International, vol. 43, pp. 1628-1631, 2017. 